Original Article - Clinical Science

\title{
Retinal Ganglion Cell Neuronal Damage in Diabetes and Diabetic Retinopathy
}

Dorothy SK Ng BOptom(Hons), ${ }^{1,3}$ Peggy PC Chiang PhD, ${ }^{1}$ Gavin Tan MRCS, ${ }^{1,2}$ Chui Min Gemmy Cheung MBBS FRCOphth, ${ }^{1,2}$ Ching Yu Cheng MD PhD, ${ }^{1,2,3}$ Carol Y Cheung PhD, ${ }^{1,2}$ Tien Y Wong MD PhD, ${ }^{1,2,3}$ Ecosse L Lamoureux MSC PhD ${ }^{1,2,5}$ and Mohammad Kamran I kram MD PhD ${ }^{1,2,4}$

${ }^{1}$ Singapore Eye Research Institute, Singapore National Eye Centre, Singapore

2 Duke-NUS Graduate Medical School, National University of Singapore, Singapore

${ }^{3}$ Department of Ophthalmology, Yong Loo Lin School of Medicine, National University of Singapore, Singapore

${ }^{4}$ Memory Aging \& Cognition Centre, National University Health System, Singapore

${ }^{5}$ Centre for Eye Research Australia, Royal Victorian Eye and Ear Hospital, University of Melbourne, Melbourne, VIC, Australia

Correspondence: Dr Ecosse L Lamoureux, Singapore Eye Research Institute, The Academia, 20 College Road, Discovery Tower Level 6, Singapore 169856

E-mail: ecosse@unimelb.edu.au

Short running title: Ganglion Cell Damage in Diabetes and DR

Received 1 October 2015; accepted 4 February 2016

Conflict of interest: None

This is the author manuscript accepted for publication and has undergone full peer review but has not been through the copyediting, typesetting, pagination and proofreading process, which may lead to differences between this version and the Version of Record. Please cite this article as doi: $10.1111 /$ ceo.12724

This article is protected by copyright. All rights reserved. 
Funding sources: National Medical Research Council, Singapore (grant no.:

NMRC/CG/SERI/2010) and the Biomedical Research Council, Singapore (grant no.: $08 / 1 / 35 / 19 / 550)$. The sponsor or funding organization had no role in the design or conduct of this research.

\section{ABSTRACT}

Background: To examine the association of diabetes and diabetic retinopathy (DR) with retinal ganglion cell (RGC) loss.

Design: Observational case-control study.

Participants: Type 2 diabetes cases and age-gender matched controls without diabetes.

Methods: Spectral-domain optical coherence tomography (OCT) parameters of RGCS were calculated after automated segmentation of macular scans. DR severity was graded on fundus photographs using the modified Airlie House Classification system. Generalized estimating equation was used to compare OCT parameters between cases and controls, adjusted for covariates.

Main Outcome Measures: Average ganglion cell-inner plexiform layer (GC-IPL) and average retinal nerve fibre layer (RNFL) thicknesses.

Results: We analyzed 227 cases and 227 controls. The mean age (years) of cases was 58.3 and controls was $58.1(P=0.13)$. Among cases, 101 had none, 25 had mild and 101 had moderate or severe DR. Compared with controls, GC-IPL and RNFL were

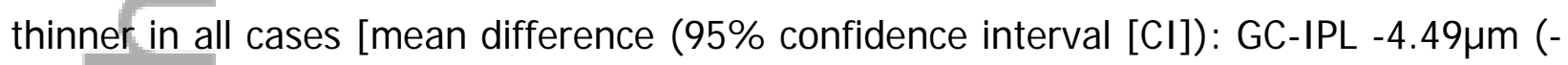

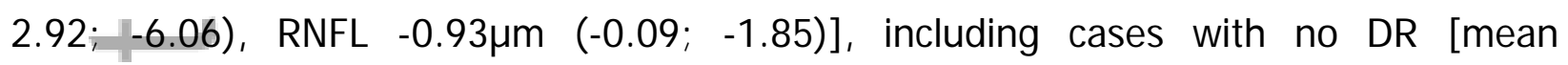

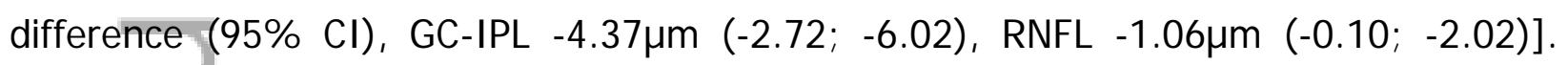
Cases with any DR had thinner GC-IPL than controls [mean difference $(95 \% \mathrm{Cl})$ : GCIPL $-4.81 \mu \mathrm{m}(-2.12 ;-7.50)$ ]. Among cases, subjects with moderate or severe DR had 
thinner GC-IPL than subjects with no DR [mean difference (95\% Cl): GC-IPL $-2.07 \mu \mathrm{m}$ (-0.08; -4.07)].

Conclusions: RGC loss is present in subjects with diabetes and no DR, and is progressive in moderate or severe DR. RGC neuronal damage in diabetes and DR can be clinically detected using OCT.

Keywords: retinal ganglion cell, neuronal damage, diabetes, diabetic retinopathy, optical coherence tomography

\section{NTRODUCTION}

Diabetic retinopathy (DR) remains the leading cause of preventable blindness in working-aged people. $(1,2)$ DR is clinically characterized by the observation of apparent microvascular lesions (e.g. microaneurysms and hard exudates). However, apparent microvascular lesions do not timely reflect retinal microvascular damage because insidious vascular changes as reflected by vessel calibre alterations would have developed prior to the incidence and progression of DR.(3-5) Furthermore, experimental studies have extensively shown that retinal ganglion cells (RGCs) are damaged in diabetes suggesting that DR also has a significant neuronal component underlying its pathogenesis. $(6,7)$ However, the clinical evaluation of neuronal damage in diabetes and DR is still not well-understood.

Advances in the analysis of optical coherence tomography (OCT) derived images with newly developed algorithms, have enabled objective quantification of structural RGC loss at specific inner layers of the retina.(8) In comparison to routine fundus examination techniques, OCT gives direct visualization of the transparent neurosensory retina that is otherwise largely not visible in slit-lamp indirect biomicroscopy.(9) 
Recent studies examining macular RGCs in persons with diabetes (with and without DR) using OCT to quantify changes in the inner neuronal layers of the retina have produced inconsistent findings. Data from these OCT studies could not agree with the evidence of RGC damage preceding the onset of apparent microvascular DR lesions, as reported by studies using other in vivo techniques, and histological materials from postmortem human retinae and animal models with diabetes. $(7,10-12)$ This conflicting evidence is observed in a number of OCT studies by van Dijk et al.,(13-15) which demonstrated that RGC loss is only significantly associated with the onset of apparent microvascular DR lesions. While the study by Vujosevic et al.,(16) found RGC loss prior to the onset of apparent microvascular DR lesions, this finding was not supported by Araszkiewicz et al.,(17) who found thicker inner layers of the retina in subjects with diabetes. Furthermore, studies by Demir et al.,(18) and Park et al.,(19) examining RGC loss with increased severity of DR have found no significant association. $(18,19)$ It is also important to note that previous OCT studies had inadequate attempt to control for the confounding effect of glycemic control, blood pressure, diabetes duration and ocular axial length. In view of these factors, we further evaluate the association of diabetes and DR with RGC loss.

\section{METHODS}

We used an observational matched case-control study design. The study was approved by the ethics committee of SingHealth Centralised Institutional Review Board, and conducted in accordance to the tenets of the Declaration of Helsinki. Written informed consent was obtained from each participant after explanation of the nature and possible consequences of the study. 
Study population

Cases were Chinese patients with type 2 diabetes with and without DR, ages 40-80 years, and recruited into the Diabetes Management Project in Singapore. The Diabetes Management Project is a cross-sectional study investigating the factors influencing an effective diabetes self-management in diabetic patients with and without DR.(20) Patients with diabetes attending the Diabetic Retinopathy Service outpatient clinic at the Singapore National Eye Centre for ophthalmological examination of DR state between December 2010 and March 2013 were recruited. These recruited patients were free of cognitive impairment as assessed by the 6-item cognitive impairment test.(21) Medical records were used to verify the diagnosis of diabetes based on glycosylated haemoglobin ( $\mathrm{HbA} 1 \mathrm{c}$ ) $\geq 6.5 \%$. Exclusion criteria were history of glaucoma or uveitis; presence of significant media opacity, including dense cataract or vitreous hemorrhage; retinopathy that was non-diabetic in nature, epiretinal membrane or diabetic macular edema as determined by grading of fundus photographs and/or OCT images; and previous retinal laser photocoagulation or retinal surgery.

Eligible cases were matched to controls selected from the Singapore Chinese Eye Study. Controls were volunteers without diabetes and/or any ocular disease in both eyes, and matched with cases on the basis of age ( \pm 5 years) and gender in a 1 control: 1 case ratio. The Singapore Chinese Eye Study is a population-based cross-sectional study of eye diseases in Chinese adults residing in Singapore and its methodology has been reported in detail elsewhere.(22) 
One study eye per participant was selected for inclusion. The study eye of each case was selected as the worse of the 2 eyes based on the assigned retinopathy severity level (as defined below), while the study eye of each control was randomly selected.

Spectral-domain optical coherence tomography retinal scanning After pupil dilation using tropicamide $1 \%$ and phenylephrine hydrochloride $2.5 \%$, retinal scanning was performed using Cirrus HD-OCT (Carl Zeiss Meditec, Dublin, CA.) to obtain measurements of the ganglion cell-inner plexiform layer (GC-IPL), the retinal nerve fibre layer (RNFL) and the outer retina. Cirrus HD-OCT is a commercially available spectral-domain OCT device with a scan speed of 27,000 axial scans per second and axial resolution of $5 \mu \mathrm{m}$.(23) One macular scan was acquired using the Macular Cube $512 \times 128$ scan protocol where a $6 \times 6 \mathrm{~mm}$ area centered on the fovea was scanned with 128 horizontal B-scans, each consisting of 512 A-scans per B-scan (total of 65,536 sampled points) within a scan time of 2.4 seconds in each eye.(24) The automated Ganglion Cell Analysis algorithm, incorporated in Cirrus HD-OCT software version 6.0 was used to demarcate and measure thicknesses of three separate intraretinal layers: GC-IPL, RNFL and outer retina. These measurements were obtained within an elliptical annulus centered on the fovea based on the three-dimensional data generated from the Macular Cube 512X128 scan protocol. Of the elliptical annulus, the size of the inner ring was chosen to exclude the area where the ganglion cell layer is thin and difficult to detect, whereas the size and shape of the outer ring were chosen to conform closely to the real macular anatomy, where the ganglion cell layer is thickest in normal eyes (Fig. 1A).(8) The Ganglion Cell Analysis algorithm measured thicknesses of the GC-IPL, the RNFL and the outer retina by average and six equally sized sectors (three sectors on either side of the horizontal midline). Thicknesses were calculated as the distance between two segmented hypereflective intraretinal layers: RNFL thickness, which is the 
distance between the inner limiting membrane and outer boundary of the RNFL; GC-IPL thickness, which is the distance between outer boundaries of the RNFL and the inner plexiform layer; and outer retinal thickness, which is the distance between outer plexiform layer and the retinal pigment epithelium (Fig. 1B). Rescanning was performed if a motion artifact (indicated by blood vessel discontinuity) was detected. Images with motion artifact, centration error, algorithm segmentation error or signal strength of less than six were excluded from the analysis.

\section{Assessment of diabetic retinopathy severity}

Retinal photography was performed using a standardized protocol.(25) Digital colour fundus photographs were taken using a 45-degree digital retinal camera (Canon CR-DGi with 10D SLR body; Canon, Tokyo, Japan) after pupil dilation. Two retinal photographs of each eye were obtained, one centered at the optic disc and another centered at the fovea, identical with the Early Treatment Diabetic Retinopathy Study standard fields 1 and 2, respectively. (26)

Retinopathy was considered to be present if any characteristic lesion as defined by the Early Treatment Diabetic Retinopathy Study severity scale was present:(27) microaneurysms (MAs), haemorrhages, cotton wool spots (CWSs), intraretinal microvascular abnormalities (IRMAs), hard exudates (HEs), venous beading, and new vessels. For each eye, a retinopathy severity level was assigned according to a scale modified from the Airlie House Classification system, which ranges from level 10 (absence of retinopathy) to level 80 (total vitreous hemorrhage). $(25,28)$ The worse of the 2 eyes of each subject with diabetes as identified by a higher retinopathy severity level was used as the study eye. Any DR was defined as level 14 and above. We categorized the severity level into one of the four groups as defined in the Multi-Ethnic 
Study of Atherosclerosis:(25) no DR (level 10), mild DR (levels 14 to 20), moderate DR (levels 31 to 41 ) and severe DR (levels 51 to 60 and 65 to 70 ).

Baseline characteristics and potential confounders

All participants underwent monocular measurements of distance visual acuity in logarithmic minimal angle resolution, static refraction and axial length. The static refraction was measured using an autorefractor (Canon RK 5 Auto Ref-Keratometer, Canon Inc., Ltd., Tochigiken, Japan). Spherical equivalent refraction was calculated as the sum of the spherical value and half of the cylindrical value. Axial length was measured with a noncontact partial coherence laser interferometry (IOLMaster Version 3.01; Carl Zeiss Meditect AG, J ena, Germany).

Systolic and diastolic blood pressures were measured using a digital automatic blood pressure monitor (Dinamap Model Pro Series DP110X-RW, 100V2; GE Medical Systems Information Technologies, Inc., Milwaukee, WI). Mean arterial blood pressure was calculated as one-third of systolic plus two-thirds of diastolic blood pressure. Hypertension was defined as systolic blood pressure $\geq 140 \mathrm{mmHg}$, diastolic blood pressure $\geq 90 \mathrm{mmHg}$, or self-reported physician diagnosis of hypertension. Non-fasting venous blood samples were obtained and analyzed the Singapore General Hospital for biochemical testing of serum total, high-density lipoprotein (HDL) and low-density lipoprotein (LDL) cholesterol, HbAlc, and random serum glucose. Other potential confounders that could influence the association, including age, gender, and diabetes duration were identified and recorded. $(23,29)$

Statistical analysis 
Continuous variables were reported as mean (standard deviation) and median (interquartile range) if not normally distributed, and matched pairs were compared with paired $t$-test for normally distributed data or Wilcoxon signed rank test if highly skewed.(30) Categorical variables were reported as frequency (percentage) and matched pairs were compared with McNemar's test. We used generalized estimating equation method to account for the correlated data arising from the relatedness of case and"control.(31) We adjusted for residual confounding effect of age, gender, axial length, OCT signal strength, $\mathrm{HbAlc}$, and mean arterial blood pressure. For the comparison of intraretinal layer thickness between DR severity levels, we additionally adjusted for diabetes duration. All statistical tests were two-sided. A value of $P<0.05$ was considered statistically significant and $95 \%$ confidence interval $(\mathrm{Cl})$ was calculated. Statistical analysis was performed using SPSS (version 19.0, SPSS Inc., Chicago, IL).

\section{RESULTS}

Matching on the basis of age and gender yielded 227 cases and 227 controls for analysis. In general, subjects with diabetes had significantly higher random serum glucose level and HbAlc; lower diastolic blood pressure, and total, HDL and LDL cholesterol level; poorer distance visual acuity and greater myopic spherical equivalent refraction than controls (Table $\mathbf{1}$ ). Subjects with diabetes were more likely to have hypertension than controls. Among subjects with diabetes, 101 had no, 25 mild, 92 moderate and 9 severe DR. Due to the small number of cases in the severe category, these were combined with the moderate group $(n=101)$.

\section{Association of diabetes with retinal ganglion cell loss}


Table 2 shows the mean difference in intraretinal layer thickness between subjects with diabetes and controls after adjustment for age, gender, axial length, OCT signal strength, $\mathrm{HbAlc}$, and mean arterial blood pressure. All subjects with diabetes (with and without DR) had significantly thinner average GC-IPL and average RNFL, but not average outer retinal layer than controls. The average GC-IPL was $4.49 \mu \mathrm{m}$ thinner (95\% $\mathrm{Cl}: 2.92$ to 6.06$)$ and the average RNFL was $0.93 \mu \mathrm{m}$ thinner (95\% Cl: 0.09 to 1.85 ) in all subjects with diabetes than controls. When stratified by DR status among cases (Table 2), subjects with diabetes and no DR had a thinning of the average GCIPL by $4.37 \mu \mathrm{m}$ ( $95 \% \mathrm{Cl}: 2.72$ to 6.02 ) and thinning of the average RNFL by $1.06 \mu \mathrm{m}$ (95\% $\mathrm{Cl}: 0.10$ to 2.02 ) when compared with controls. In subjects with any $\mathrm{DR}$, the average GC-IPL was $4.81 \mu \mathrm{m}$ thinner $(95 \% \mathrm{Cl} 2.12$ to 7.50$)$ than controls. When evaluated with a reduced age-gender adjusted model, effect sizes of these associations remained similar, except for average RNFL thinning in cases with no DR that did not reach significance (results not shown). There was no reduction in average outer retinal thickness in diabetic subjects with no DR or any DR when compared with controls.

Association of diabetic retinopathy with retinal ganglion cell loss

As shown in Table 3, after additional adjustment for diabetes duration, together with age, gender, axial length, OCT signal strength, HbAlc, and mean arterial blood pressure, the average GC-IPL in subjects with moderate or severe DR was $2.07 \mu \mathrm{m}$ thinner ( $95 \% \mathrm{Cl}: 0.08$ to 4.07 ) than subjects with diabetes and no DR. The association and its effect size remained similar even when diabetes duration was removed from the model (results not shown). The average GC-IPL was not significantly thinner between subjects with mild DR and subjects with diabetes and no DR. There was no significant reduction in average RNFL thickness between DR severity levels. 


\section{DISCUSSION}

The present study demonstrates that, in subjects with diabetes, RGC neurons are vulnerable to damage prior to the onset of apparent microvascular DR lesions when compared with healthy controls, and such RGC damage is progressive with subsequent severe forms of DR development. OCT measures indicative of GC-IPL and RNFL thinning, but not outer retinal thinning was associated with diabetic subjects with no clinically apparent DR. Furthermore, subjects with moderate or severe DR had thinner GC-IPL than subjects with diabetes and no DR.

The measurement of the GC-IPL and the RNFL using OCT gives a gross cumulative quantitative assessment of RGCs. An underlying assumption here is that RGC damage at the cellular level is cumulative enough to be detected clinically with OCT. van Dijk et al.,(13-15) studied macular neuronal damage in persons with type 1 and type 2 diabetes using time-domain and spectral-domain OCT, and found a thinning of the ganglion cell layer or the RNFL in subjects with existing apparent signs of microvascular damage, but not in subjects who had no apparent microvascular DR lesions. While Vujosevic et al.,(16) found RGC loss in diabetic subjects who had no apparent microvascular DR lesions, RGC loss was reflected by a thinning only of the RNFL but not the GC-IPL. For the purpose of quantifying macular RGC loss, the GC-IPL offers a theoretical advantage over the RNFL. Reason being, the size of cell bodies that reside in the ganglion cell layer is 10 to 20 times the diameter of their axons in the RNFL,(32) and thus measurement of the relatively thicker GC-IPL may be more sensitive for detecting pathological change than measurement of RNFL thickness. As opposed to previous studies, the present study had a considerably larger sample size, and found a thinning of both the GC-IPL and the RNFL in diabetic subjects who have not yet 
developed apparent microvascular DR lesions. These changes mirror findings of electroretinography studies in diabetic subjects that reported neuronal dysfunction before the onset of clinically apparent DR. $(33,34)$ Together, these data suggest that neuronal apoptosis, the likely mechanism of RGC loss, may precede retinal microvascular pathology in diabetes. $(7,35)$ Nonetheless, one cannot exclude the possibility that subtle as yet clinically undetected microvascular pathology could have existed before (concurrent with) GC-IPL and RNFL thinning. Therefore, the present study's OCT findings in diabetic subjects with no apparent microvascular lesions may reflect the discrepancy of scale between the relatively macroscopic clinical DR grading and anatomic inquiry of the inner retinal microenvironment with OCT. Changes in OCT parameters of the inner neuronal layers of the retina that appear to precede clinically apparent DR could provide clinicians with a potentially valuable biomarker of the earliest stages of DR.

Among subjects with diabetes, the present study demonstrated that subjects with moderate or severe DR had thinner GC-IPL than subjects with no DR. This suggests that RGC loss, as reflected by GC-IPL thinning which begins before microvascular lesions become apparent is progressive in subsequent severe forms of DR development. Previous studies by Demir et al.(18) and Park et al.,(19) using different OCT algorithms to measure different RGC parameters, such as ganglion cell complex thickness, did not demonstrate a significant association of RGC loss with increased DR severity. Although the GC-IPL and the RNFL were measured as a combined thickness, it is still reasonable to expect changes in the OCT parameter, should there be presence of neuronal damage, as loss of ganglion cell bodies will lead to corresponding axonal loss.(36) Nonetheless, the present study implemented an OCT algorithm that automatically demarcated the GC-IPL and the RNFL separately, as ganglion cell bodies and its axons 
may exhibit different temporal response to injurious stimuli due to their asymmetric metabolic requirements. $(37,38)$ The present study's OCT finding is supported by electroretinography study that recorded abnormal electrical responses, suggesting a decreased RGC function, which not only preceded the onset of apparent microvascular DR lesions but also paralleled the severity of subsequent DR.(39) Furthermore, the retinal site of neuronal dysfunction corresponded to the locality of apparent microvascular DR lesions, and in a longitudinal study, even predicted retinal sites of subsequent DR. $(39,40)$ Taken together, these findings provide support for the hypothesis that RGC dysfunction may contribute to the breakdown of the retinal microvasculature, however further experimental work will be required to establish any casual association that is beyond the methodology of the present study. The association of GC-IPL thinning with increased DR severity observed by the present study may therefore offer an objective clinical measure of cellular response to therapeutic interventions.

Different mechanisms that may underlie the development of neuronal damage in diabetes and DR have been proposed. Glial cells, with their processes surrounding all retinal vessels release local factors to modulate retinal blood flow, and are essential for the integration of vascular and neuronal activity in the retina. $(41,42)$ It has been shown that shortly after the onset of diabetes, the ability of Müller cells (the principal glia of the retina) in the uptake of glutamate released by neurons, and to convert glutamate to glutamine was reduced. $(43,44)$ Hence, glutamate accumulates to excessive levels, $(35,45)$ which leads to uncontrolled influx of intracellular calcium ions causing neurotoxicity.(46) In diabetic retinae of animal models, glial cells (prominently at the RNFL) and RGCs have shown an increased expression of vascular endothelial growth factor (VEGF).(47) As a result, the excessive level of VEGF promotes breakdown 
of the blood-retinal barrier, and thus allows entry of circulatory harmful agents into the neuronal retina.(48) Furthermore, the toxic effects of hyperglycemia, which arise from several metabolic pathways (e.g. protein kinase $\mathrm{C}$ and formation of advanced glycation end products) not only cause circulatory disturbance to the retinal microvasculature but also enhance the production of reactive oxygen species leading to oxidative damage of retinal neurons.(49) Taken together, metabolic functions of both retinal glia and neurons are altered early in DR progression. It is plausible that altered glial function affects the integrity of both the neuronal and vascular elements of the retina.(9) Consequently, this disturbs the close interaction between neuronal activity and retinal blood flow, and hinders the homeostasis required for normal retinal function.(50) Therefore, maintaining retinal glia and neuronal functions may normalize retinal circulation to prevent or delay DR progression.(41)

Several limitations of the current study need to be discussed. Firstly, we were not able to examine the link with severe DR specifically, as we only had small number of cases with severe DR. Secondly, the cross-sectional design did not give us an opportunity to examine the temporal link between neuronal damage and the appearance of microvascular lesions. Lastly, the RNFL thickness was measured at the macular region, where the layer is anatomically thinner than the region around the optic nerve head, where it is usually measured. This thinner RNFL region may have introduced more measurement error. Strengths of the current study include the measurement of retinal parameters at the macular region using a reliable and reproducible spectral-domain OCT algorithm.(8) Furthermore, with the current algorithm we were able to measure specific layers of the retina (e.g. GC-IPL). Standardized protocols were strictly followed during retinal photography and in the grading of DR severity to ensure reliable 
characterization of DR states. Lastly, as opposed to previous studies, the effect of several potential confounders was controlled to manifest independent associations.

In summary, the present study demonstrates that RGC loss quantified by OCT is present in diabetic subjects who had no apparent microvascular DR lesions, and such neuronal damage is progressive in subsequent moderate or severe DR development. These clinical data which showed evidence of RGC loss in diabetes and DR are in agreement with that of experimental studies. Further prospective studies are required to confirm this association.

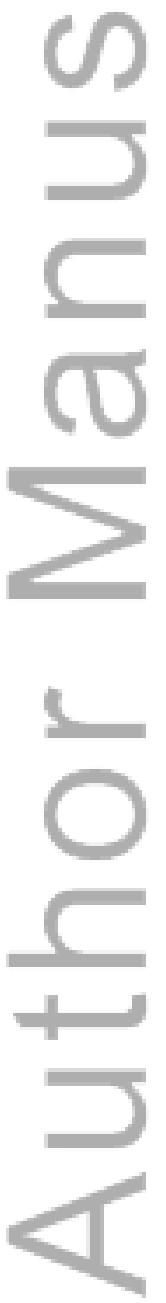

This article is protected by copyright. All rights reserved. 


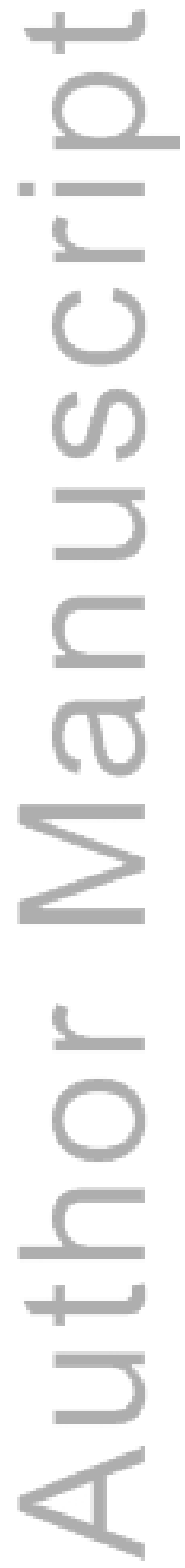

This article is protected by copyright. All rights reserved. 


\section{REFERENCES}

1. Cheung N, Wong IY, Wong TY. Ocular anti-VEGF therapy for diabetic retinopathy: overview of clinical efficacy and evolving applications. Diabetes care. 2014 Apr;37(4):900-5. PubMed PMID: 24652721. Epub 2014/03/22. eng.

2. Cheung N, Mitchell P, Wong TY. Diabetic retinopathy. Lancet. $2010 \mathrm{Jul}$ " 10;376(9735):124-36. PubMed PMID: 20580421. Epub 2010/06/29. eng.

3. Broe R, Rasmussen ML, Frydkjaer-Olsen U, Olsen BS, Mortensen HB, Hodgson L, et al. Retinal vessel calibers predict long-term microvascular complications in type 1 diabetes: the Danish Cohort of Pediatric Diabetes 1987 (DCPD1987). Diabetes. 2014 Nov;63(11):3906-14. PubMed PMID: 24914239. Epub 2014/06/11. eng.

4. Cheung N, Rogers SL, Donaghue KC, Jenkins AJ, Tikellis G, Wong TY. Retinal arteriolar dilation predicts retinopathy in adolescents with type 1 diabetes. Diabetes care. 2008 Sep;31(9):1842-6. PubMed PMID: 18523143. Pubmed Central PMCID: PMC2518356. Epub 2008/06/05. eng.

5. Roy MS, Klein R, Janal MN. Retinal venular diameter as an early indicator of progression to proliferative diabetic retinopathy with and without high-risk characteristics in African Americans with type 1 diabetes mellitus. Archives of ophthalmology. 2011 Jan;129(1):8-15. PubMed PMID: 21220623. Epub 2011/01/12. eng.

6. Barber AJ, Gardner TW, Abcouwer SF. The significance of vascular and neural apoptosis to the pathology of diabetic retinopathy. Investigative ophthalmology \& visual science. 2011 Feb;52(2):1156-63. PubMed PMID: 21357409. Pubmed Central PMCID: PMC3053099. Epub 2011/03/02. eng. 
7. Barber AJ, Lieth E, Khin SA, Antonetti DA, Buchanan AG, Gardner TW. Neural apoptosis in the retina during experimental and human diabetes. Early onset and effect of insulin. J Clin Invest. 1998 Aug 15;102(4):783-91. PubMed PMID: 9710447. Pubmed Central PMCID: PMC508941. Epub 1998/08/26. eng.

8. Mwanza JC, Oakley JD, Budenz DL, Chang RT, Knight OJ, Feuer WJ. Macular ganglion cell-inner plexiform layer: automated detection and thickness reproducibility with spectral domain-optical coherence tomography in glaucoma. Investigative ophthalmology \& visual science. 2011;52(11):8323-9. PubMed PMID: 21917932. Pubmed Central PMCID: PMC3208140. Epub 2011/09/16. eng.

9. Lieth E, Gardner TW, Barber AJ, Antonetti DA. Retinal neurodegeneration: early pathology in diabetes. Clinical \& experimental ophthalmology. $2000 \mathrm{Feb}$;28(1):38. PubMed PMID: 11345341. Epub 2001/05/10. eng.

10. Aizu $\mathrm{Y}$, Oyanagi $\mathrm{K}, \mathrm{Hu} \mathrm{J}$, Nakagawa $\mathrm{H}$. Degeneration of retinal neuronal processes and pigment epithelium in the early stage of the streptozotocindiabetic rats. Neuropathology : official journal of the Japanese Society of Neuropathology. 2002 Sep;22(3):161-70. PubMed PMID: 12416555. Epub 2002/11/06. eng.

11. Chihara E, Matsuoka T, Ogura Y, Matsumura M. Retinal nerve fiber layer defect as an early manifestation of diabetic retinopathy. Ophthalmology. 1993 Aug; 100(8):1147-51. PubMed PMID: 8341494. Epub 1993/08/01. eng.

12. Lopes de Faria JM, Russ H, Costa VP. Retinal nerve fibre layer loss in patients with type 1 diabetes mellitus without retinopathy. $\mathrm{Br} J$ Ophthalmol. 2002 Jul;86(7):725-8. PubMed PMID: 12084737. Pubmed Central PMCID: PMC1771182. Epub 2002/06/27. eng.

13. van Dijk HW, Verbraak FD, Kok PH, Garvin MK, Sonka M, Lee K, et al. Decreased retinal ganglion cell layer thickness in patients with type 1 diabetes. Investigative 
ophthalmology \& visual science. 2010 Jul;51(7):3660-5. PubMed PMID: 20130282. Pubmed Central PMCID: PMC2904016. Epub 2010/02/05. eng.

14. van Dijk HW, Verbraak FD, Kok PH, Stehouwer M, Garvin MK, Sonka M, et al. Early neurodegeneration in the retina of type 2 diabetic patients. Investigative ophthalmology \& visual science. 2012 May;53(6):2715-9. PubMed PMID: 22427582. Pubmed Central PMCID: PMC3366721. Epub 2012/03/20. eng.

15. "' van Dijk HW, Kok PH, Garvin M, Sonka M, Devries JH, Michels RP, et al. Selective loss of inner retinal layer thickness in type 1 diabetic patients with minimal diabetic retinopathy. Investigative ophthalmology \& visual science. 2009 Jul;50(7):3404-9. PubMed PMID: 19151397. Pubmed Central PMCID: PMC2937215. Epub 2009/01/20. eng.

16. Vujosevic S, Midena E. Retinal layers changes in human preclinical and early clinical diabetic retinopathy support early retinal neuronal and Muller cells alterations. Journal of diabetes research. 2013;2013:905058. PubMed PMID: 23841106. Pubmed Central PMCID: PMC3694491. Epub 2013/07/11. eng.

17. Araszkiewicz A, Zozulinska-Ziolkiewicz D, Meller M, Bernardczyk-Meller J, Pilacinski S, Rogowicz-Frontczak A, et al. Neurodegeneration of the retina in type 1 diabetic patients. Pol Arch Med Wewn. 2012;122(10):464-70. PubMed PMID: 22910230. Epub 2012/08/23. eng.

18. Demir M, Oba E, Sensoz H, Ozdal E. Retinal nerve fiber layer and ganglion cell complex thickness in patients with type 2 diabetes mellitus. Indian J Ophthalmol. 2014 Jun;62(6):719-20. PubMed PMID: 25005202. Pubmed Central PMCID: PMC4131327. Epub 2014/07/10. eng.

19. 'Park HY, Kim IT, Park CK. Early diabetic changes in the nerve fibre layer at the macula detected by spectral domain optical coherence tomography. $\mathrm{Br} \mathrm{J}$ 
Ophthalmol. 2011 Sep;95(9):1223-8. PubMed PMID: 21216799. Epub 2011/01/11. eng.

20. Lamoureux EL, Fenwick E, Xie J, McAuley A, Nicolaou T, Larizza M, et al. Methodology and early findings of the Diabetes Management Project: a cohort study investigating the barriers to optimal diabetes care in diabetic patients with and without diabetic retinopathy. Clinical \& experimental ophthalmology. 2012 Jan-Feb;40(1):73-82. PubMed PMID: 21902788. Epub 2011/09/10. eng.

21. Brooke $P$, Bullock R. Validation of a 6 item cognitive impairment test with a view to primary care usage. Int J Geriatr Psychiatry. 1999 Nov; 14(11):936-40. PubMed PMID: 10556864. Epub 1999/11/11. eng.

22. Lavanya R, Jeganathan VS, Zheng $Y$, Raju P, Cheung N, Tai ES, et al. Methodology of the Singapore Indian Chinese Cohort (SICC) eye study: quantifying ethnic variations in the epidemiology of eye diseases in Asians. Ophthalmic Epidemiol. 2009 Nov-Dec;16(6):325-36. PubMed PMID: 19995197. Epub 2009/12/10. eng.

23. Koh VT, Tham YC, Cheung CY, Wong WL, Baskaran M, Saw SM, et al. Determinants of ganglion cell-inner plexiform layer thickness measured by highdefinition optical coherence tomography. Investigative ophthalmology \& visual science. 2012 Aug;53(9):5853-9. PubMed PMID: 22836772. Epub 2012/07/28. eng.

24. Wolf-Schnurrbusch UE, Ceklic L, Brinkmann CK, Iliev ME, Frey M, Rothenbuehler $\mathrm{SP}$, et al. Macular thickness measurements in healthy eyes using six different optical coherence tomography instruments. Investigative ophthalmology \& visual science. 2009 Jul;50(7):3432-7. PubMed PMID: 19234346. Epub 2009/02/24. eng. 
25. Wong TY, Klein R, Islam FM, Cotch MF, Folsom AR, Klein BE, et al. Diabetic retinopathy in a multi-ethnic cohort in the United States. Am J Ophthalmol. 2006 Mar; 141(3):446-55. PubMed PMID: 16490489. Pubmed Central PMCID: PMC2246042. Epub 2006/02/24. eng.

26. Klein R, Klein BE, Magli YL, Brothers RJ, Meuer SM, Moss SE, et al. An alternative method of grading diabetic retinopathy. Ophthalmology. 1986 Sep;93(9):1183-7.

" 'PubMed PMID: 3101021. Epub 1986/09/01. eng.

27. Grading diabetic retinopathy from stereoscopic color fundus photographs--an extension of the modified Airlie House classification. ETDRS report number 10. Early Treatment Diabetic Retinopathy Study Research Group. Ophthalmology. 1991 May; 98(5 Suppl): 786-806. PubMed PMID: 2062513. Epub 1991/05/01. eng.

28. Diabetic retinopathy study. Report Number 6. Design, methods, and baseline results. Report Number 7. A modification of the Airlie House classification of diabetic retinopathy. Prepared by the Diabetic Retinopathy. Investigative ophthalmology \& visual science. 1981 Jul;21(1 Pt 2):1-226. PubMed PMID: 7195893. Epub 1981/07/01. eng.

29. van Leiden HA, Dekker JM, Moll AC, Nijpels G, Heine RJ, Bouter LM, et al. Risk factors for incident retinopathy in a diabetic and nondiabetic population: the Hoorn study. Archives of ophthalmology. 2003 Feb;121(2):245-51. PubMed PMID: 12583792. Epub 2003/02/14. eng.

30. Niven DJ, Berthiaume LR, Fick GH, Laupland KB. Matched case-control studies: a review of reported statistical methodology. Clinical epidemiology. 2012;4:99-110.

PubMed PMID: 22570570. Pubmed Central PMCID: PMC3346204. Epub 2012/05/10. eng. 
31. Lin IF, Lai MY, Chuang PH. Analysis of matched case-control data with incomplete strata: applying longitudinal approaches. Epidemiology. 2007 J ul;18(4):446-52. PubMed PMID: 17525695. Epub 2007/05/26. eng.

32. Ishikawa H, Stein DM, Wollstein G, Beaton S, Fujimoto J G, Schuman JS. Macular segmentation with optical coherence tomography. Investigative ophthalmology \& visual science. 2005 Jun;46(6):2012-7. PubMed PMID: 15914617. Pubmed " Central PMCID: PMC1939723. Epub 2005/05/26. eng.

33. Juen S, Kieselbach GF. Electrophysiological changes in juvenile diabetics without retinopathy. Archives of ophthalmology. 1990 Mar;108(3):372-5. PubMed PMID: 2310337. Epub 1990/03/01. eng.

34. Simonsen SE. The value of the oscillatory potential in selecting juvenile diabetics at risk of developing proliferative retinopathy. Acta Ophthalmol (Copenh). 1980 Dec;58(6):865-78. PubMed PMID: 7331773. Epub 1980/12/01. eng.

35. Lieth E, Barber AJ, Xu B, Dice C, Ratz MJ, Tanase D, et al. Glial reactivity and impaired glutamate metabolism in short-term experimental diabetic retinopathy. Penn State Retina Research Group. Diabetes. 1998 May;47(5):815-20. PubMed PMID: 9588455. Epub 1998/05/20. eng.

36. Huang G, Luo T, Gast TJ, Burns SA, Malinovsky VE, Swanson WH. Imaging Glaucomatous Damage Across the Temporal Raphe. Investigative ophthalmology \& visual science. 2015 Jun;56(6):3496-504. PubMed PMID: 26047040. Pubmed Central PMCID: PMC4464103. Epub 2015/06/06. eng.

37. Bristow EA, Griffiths PG, Andrews RM, Johnson MA, Turnbull DM. The distribution - of mitochondrial activity in relation to optic nerve structure. Archives of ophthalmology. 2002 Jun;120(6):791-6. PubMed PMID: 12049585. Epub 2002/06/07. eng. 
38. Kalesnykas G, Oglesby EN, Zack DJ, Cone FE, Steinhart MR, Tian J, et al. Retinal ganglion cell morphology after optic nerve crush and experimental glaucoma. Investigative ophthalmology \& visual science. 2012 J un;53(7):3847-57. PubMed PMID: 22589442. Pubmed Central PMCID: PMC3630905. Epub 2012/05/17. eng.

39. Fortune B, Schneck ME, Adams AJ. Multifocal electroretinogram delays reveal local retinal dysfunction in early diabetic retinopathy. Investigative " ophthalmology \& visual science. 1999 Oct;40(11):2638-51. PubMed PMID: 10509661. Epub 1999/10/06. eng.

40. Han Y, Bearse MA, J r., Schneck ME, Barez S, Jacobsen CH, Adams AJ. Multifocal electroretinogram delays predict sites of subsequent diabetic retinopathy. Investigative ophthalmology \& visual science. 2004 Mar;45(3):948-54. PubMed PMID: 14985316. Epub 2004/02/27. eng.

41. Nakahara T, Mori A, Kurauchi Y, Sakamoto K, Ishii K. Neurovascular interactions in the retina: physiological and pathological roles. Journal of pharmacological sciences. 2013;123(2): 79-84. PubMed PMID: 24067498. Epub 2013/09/27. eng.

42. Gardner TW, Antonetti DA, Barber AJ, LaNoue KF, Levison SW. Diabetic retinopathy: more than meets the eye. Surv Ophthalmol. 2002 Dec;47 Suppl 2:S253-62. PubMed PMID: 12507627. Epub 2003/01/01. eng.

43. Lieth $\mathrm{E}$, LaNoue KF, Antonetti DA, Ratz M. Diabetes reduces glutamate oxidation and glutamine synthesis in the retina. The Penn State Retina Research Group. Exp Eye Res. 2000 Jun;70(6):723-30. PubMed PMID: 10843776. Epub 2000/06/14. eng.

44. Mizutani M, Gerhardinger C, Lorenzi M. Muller cell changes in human diabetic retinopathy. Diabetes. 1998 Mar;47(3):445-9. PubMed PMID: 9519752. Epub 1998/03/31. eng. 
45. Ambati J, Chalam KV, Chawla DK, D'Angio CT, Guillet EG, Rose SJ, et al. Elevated gamma-aminobutyric acid, glutamate, and vascular endothelial growth factor levels in the vitreous of patients with proliferative diabetic retinopathy. Archives of ophthalmology. 1997 Sep;115(9):1161-6. PubMed PMID: 9298058. Epub 1997/09/23. eng.

46. Orrenius S, Nicotera P. The calcium ion and cell death. J Neural Transm Suppl. 1994;43:1-11. PubMed PMID: 7884392. Epub 1994/01/01. eng.

47. Murata T, Nakagawa K, Khalil A, Ishibashi T, Inomata H, Sueishi $K$. The relation between expression of vascular endothelial growth factor and breakdown of the blood-retinal barrier in diabetic rat retinas. Lab Invest. 1996 Apr; 74(4):819-25. PubMed PMID: 8606491. Epub 1996/04/01. eng.

48. Mathews MK, Merges C, McLeod DS, Lutty GA. Vascular endothelial growth factor and vascular permeability changes in human diabetic retinopathy. Investigative ophthalmology \& visual science. 1997 Dec;38(13):2729-41. PubMed PMID: 9418725. Epub 1998/01/07. eng.

49. Ola MS, Alhomida AS. Neurodegeneration in diabetic retina and its potential drug targets. Current neuropharmacology. 2014 Jul;12(4):380-6. PubMed PMID: 25342945. Pubmed Central PMCID: PMC4207077. Epub 2014/10/25. eng.

50. Jindal V. Neurodegeneration as a primary change and role of neuroprotection in diabetic retinopathy. Molecular neurobiology. 2015 Jun;51(3):878-84. PubMed PMID: 24826918. Epub 2014/05/16. eng. 


\section{FI GURE LEGENDS}

Figure 1: Cirrus HD-OCT Ganglion Cell Analysis protocol. (A) Vertical and horizontal dimensions of the foveal centered elliptical annulus in right eye. The annulus is divided into six equally sized sectors. (B) A horizontal B-scan of Macular Cube 512X128 scan protocol with segmented retinal nerve fibre layer (the thickness was calculated as the distance between red and blue lines), ganglion cell-inner plexiform layer (the thickness was calculated as the distance between blue and yellow lines), and outer retina (the thickness was calculated as the distance between dotted lines).

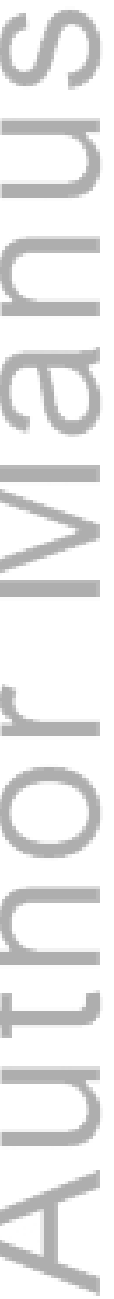


Table 1: Comparison of baseline characteristics between cases and controls

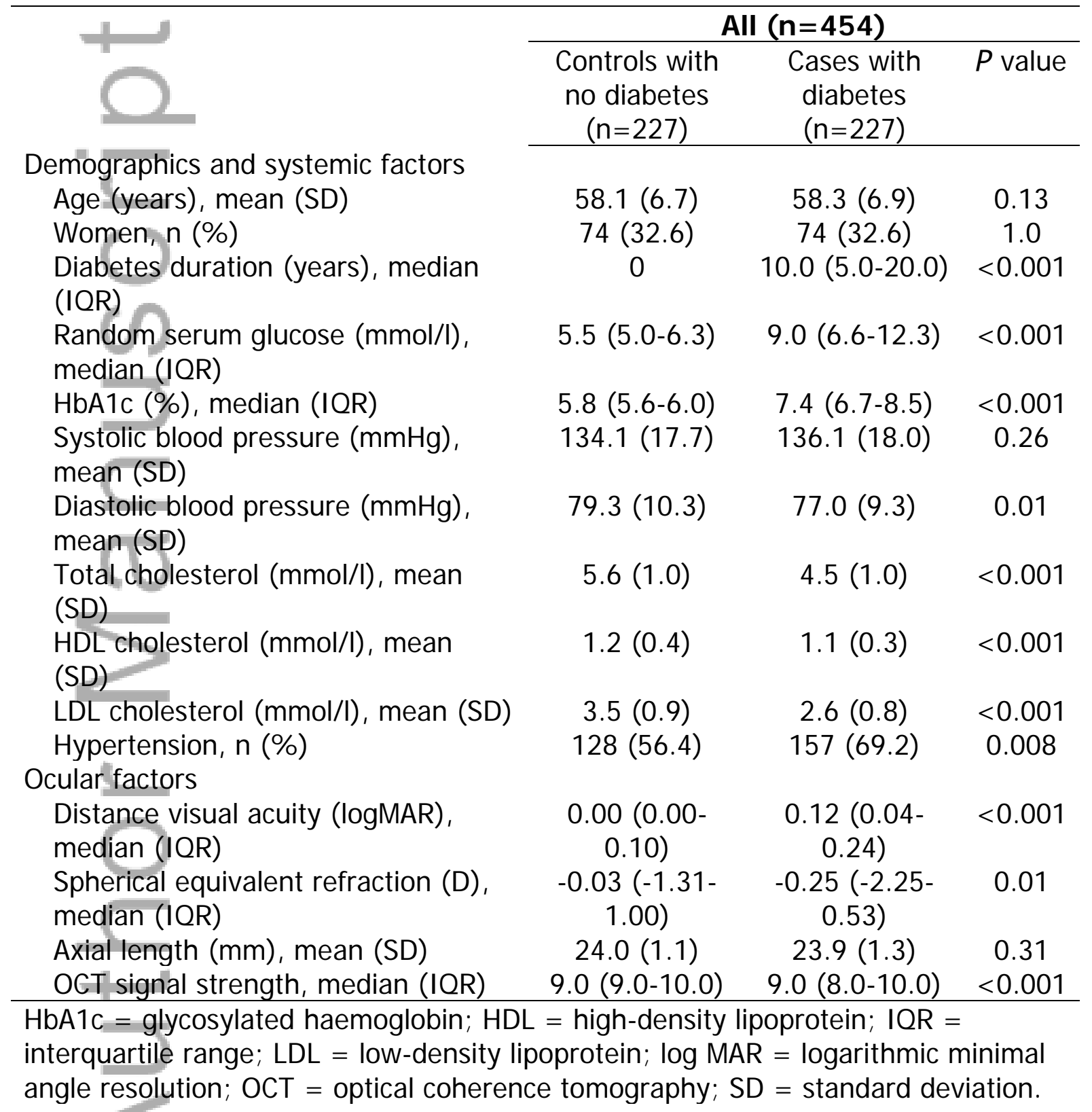




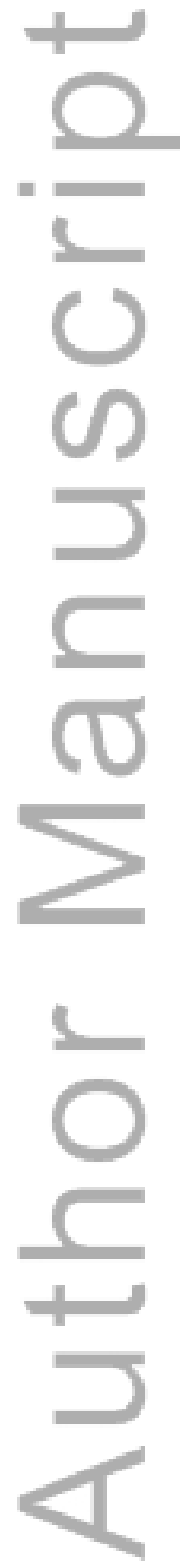

This article is protected by copyright. All rights reserved. 
Table 2: Multi-variable adjusted mean difference in $\mu \mathrm{m}$ (95\% confidence interval) in intraretinal layer thickness of retinal ganglion cells and outer retina in subjects with diabetes compared with controls

\begin{tabular}{|c|c|c|c|}
\hline ر & $\begin{array}{c}\text { Average GC-IPL } \\
\text { thickness }\end{array}$ & $\begin{array}{c}\text { Average RNFL } \\
\text { thickness }\end{array}$ & $\begin{array}{l}\text { Average outer } \\
\text { retinal thickness }\end{array}$ \\
\hline $\begin{array}{l}\text { Controls with no } \\
\text { diabetes }\end{array}$ & (Reference) & (Reference) & (Reference) \\
\hline $\begin{array}{l}\text { Cases with diabetes } \\
(\mathrm{n}=227) \\
\text { Cases stratified by DR } \\
\text { status }\end{array}$ & $\begin{array}{c}-4.49(-6.06,- \\
2.92)\end{array}$ & $\begin{array}{c}-0.93(-1.85,- \\
0.09)\end{array}$ & $\begin{array}{c}2.03(-0.08 \\
4.13)\end{array}$ \\
\hline $\begin{array}{l}\text { No DR }(n=101) \\
\text { Any DR }(n=126)\end{array}$ & $\begin{array}{c}-4.37(-6.02,- \\
2.72) \\
-4.81(-7.50,- \\
2.12) \\
\end{array}$ & $\begin{array}{c}-\mathbf{- 1 . 0 6}(-\mathbf{2 . 0 2},- \\
\mathbf{0 . 1 0 )} \\
-0.82(-2.50 \\
0.86) \\
\end{array}$ & $\begin{array}{c}1.68(-0.64, \\
4.00) \\
\mathbf{2 . 5 5 ( 0 . 0 8 ,} \\
\mathbf{5 . 0 2 )} \\
\end{array}$ \\
\hline
\end{tabular}

$\mathrm{DR}=$ diabetic retinopathy; $\mathrm{GC}-\mathrm{IPL}=$ ganglion cell-inner plexiform layer; RNFL = retinal nerve fibre layer.

Multivariate model includes age, gender, axial length, OCT signal strength, HbAlc and mean arterial blood pressure. 
Table 3: Multi-variable adjusted mean difference in $\mu \mathrm{m}$ (95\% confidence interval) in intraretinal layer thickness of retinal ganglion cells between DR severity levels among subjects with diabetes

\begin{tabular}{|c|c|c|}
\hline Subjects with diabetes & $\begin{array}{l}\text { Average GC-IPL } \\
\text { thickness }\end{array}$ & Average RNFL thickness \\
\hline No $D R(n=101)$ & (Reference) & (Reference) \\
\hline Any DR $(n=126)$ & $-1.47(-3.28,0.34)$ & $-0.03(-1.18,1.13)$ \\
\hline \multicolumn{3}{|l|}{ Stratified by DR severity } \\
\hline Mild DR ( $n=25)$ & $-0.78(-3.52,1.95)$ & $0.35(-1.46,2.16)$ \\
\hline $\begin{array}{l}\text { Moderate or severe DR } \\
(n=101)\end{array}$ & $-2.07(-4.07,-0.08)$ & $-0.35(-1.62,0.92)$ \\
\hline \multicolumn{3}{|c|}{$\begin{array}{l}\mathrm{DR}=\text { diabetic retinopathy; GC-IPL = ganglion cell-inner plexiform layer; RNFL = } \\
\text { retinal nerve fibre layer. }\end{array}$} \\
\hline
\end{tabular}

This article is protected by copyright. All rights reserved. 


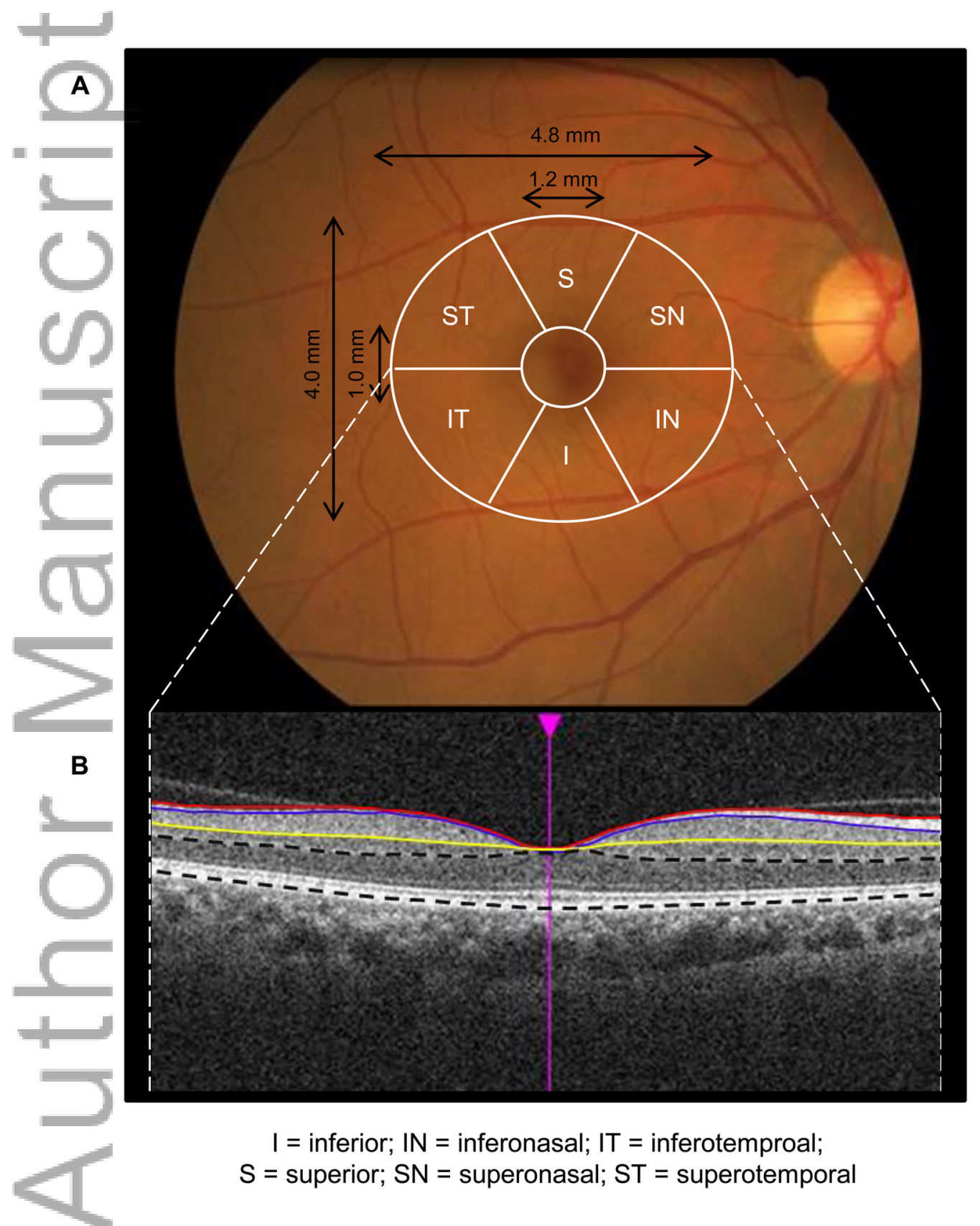

CEO_12724_F1.tif

This article is protected by copyright. All rights reserved. 


\section{University Library}

\section{- M M N E R VA A gateway to Melbourne's research publications}

Minerva Access is the Institutional Repository of The University of Melbourne

Author/s:

Ng, DSK;Chiang, PPC;Tan, G;Cheung, CMG;Cheng, C-Y;Cheung, CY;Wong, TY;Lamoureux, EL;Ikram, MK

Title:

Retinal ganglion cell neuronal damage in diabetes and diabetic retinopathy

Date:

2016-05-01

Citation:

Ng, D. S. K., Chiang, P. P. C., Tan, G., Cheung, C. M. G., Cheng, C. -Y., Cheung, C. Y., Wong, T. Y., Lamoureux, E. L. \& Ikram, M. K. (2016). Retinal ganglion cell neuronal damage in diabetes and diabetic retinopathy. CLINICAL AND EXPERIMENTAL OPHTHALMOLOGY, 44 (4), pp.243-250. https://doi.org/10.1111/ceo.12724.

Persistent Link:

http://hdl.handle.net/11343/291091 